\title{
Total Diz Replasmanı Olacak Hastada Kombine Spinal Epidural Anestezi ile Oluşan Pnömosefali: Olgu Sunumu
}

\author{
Pneumocephalus Caused by Combined Spinal Epidural Anesthesia in a Patient Who \\ Will Have Total Knee Replacement: Case Report
}

\author{
Fatih Şahin', Alkan Kibar ${ }^{2}$ \\ ${ }^{2}$ Sakarya Yenikent Devlet Hastanesi Anesteziyoloji ve Reanimasyon Kliniği, Sakarya, Türkiye \\ Yazışma Adresi / Correspondence: \\ Fatih Şahin \\ Sakarya Üniversitesi Tip Fakültesi Eğitim ve Araştırma Hastanesi Anesteziyoloji ve Reanimasyon Kliniği 54100 Sakarya-Türkiye \\ T: +905062607219 E-mail: tyflfatih16@hotmail.com \\ Geliş Tarihi / Received : 01.07.2021 Kabul Tarihi / Accepted : 13.12.2021 \\ Orcid: \\ Fatih Şahin: https://orcid.org/0000-0002-8501-0675 \\ Alkan Kibar: https://orcid.org/0000-0002-0049-929X \\ (Sakarya Tip Dergisi / Sakarya Med J 2021, 11(4):947-950) DOI: 10.31832/smj.762329
}

${ }^{1}$ Sakarya Üniversitesi Tip Fakültesi Eğitim ve Araştırma Hastanesi Anesteziyoloji ve Reanimasyon Kliniği, Sakarya, Türkiye

\footnotetext{
$\ddot{O} \mathrm{z}$

Pnömosefali intrakraniyal kompartmanların herhangi birinde hava bulunması olarak tanımlanır. Genellikle epidural anestezinin hava ile direnç kaybı yöntemi kullanılarak uygulanması sonrasında görülebilir. Bu sunumda, alt ekstremite cerrahisi için kombine spinal epidural anestezi (KSEA) sırasında pnömosefali gelişen bir hastanın irdelenmesi amaçlanmıștır. 71 yașındaki hastaya total diz replasmanı cerrahisi için KSEA uygulaması kararlaștırıldı. Postoperatif 20. saatte bilinç bulanıklığı, uykuya meyil ve konușma güçlüğü bașladı. Beyin bilgisayarlı tomografi (BT) görüntülemesinde interventriküler ve frontal alanda hava görünümü izlendi. Pnömosefali tanısı konulan hastada herhangi bir cerrahi tedavi düşünülmedi. Takiplerinde komplikasyon gözlenmeyen hastada 7. gün sonunda yapılan BT görüntülemesinde pnömosefalinin tamamen gerilediği gözlendi. 6 ay boyunca yapılan takiplerinde herhangi bir intrakraniyal patolojiye rastlanmadı. Sonuç olarak, KSEA sırasında pnömosefali gelişebileceği unutulmamalidır.

Anahtar Spinal Epidural Anestezi; Pnömosefali; Komplikasyon; Bilgisayarlı Tomografi

Pneumocephalus is defined as air in any of the intracranial compartments. It can usually be seen after the application of epidural anesthesia using the loss of resistance method with air. In this presentation, we aimed to review a patient who developed pneumocephalus during combined spinal epidural anesthesia (CSEA) for lower extremity surgery. It was decided to apply CSEA for total knee replacement surgery to a 71-year-old patient. In the 20th hour postoperatively, confusion, sleepiness and difficulty in speaking started. Air appearance in the interventricular and frontal areas was observed in the brain computed tomography (CT) imaging. No surgical treatment was considered for the patient who was diagnosed with pneumocephalus. No complications were observed in the patient's follow-up, and the pneumocephalus completely regressed in the CT imaging performed at the end of the 7th day. No intracranial pathology was found in the 6-month follow-up. In conclusion, it should not be forgotten that pneumocephalus may develop during CSEA.

Keywords Spinal Epidural Anesthesia; Pneumocephalus; Complication; Computed Tomography
} 


\section{GIIRIŞ}

Pnömosefali intrakraniyal kompartmanların herhangi birinde (intraventriküler, intraparenkimal, subaraknoid, subdural veya epidural boşluklar) hava bulunması olarak tanımlanır. ${ }^{1}$ Nöraksiyel anestezi uygulamaları sonrasında pnömosefali vakaları ortaya çıkabilmektedir. Bu durum genelde havayla direnç kaybı tekniği kullanılarak yapılan epidural uygulamaları sırasında tuohy iğnesi ile kazara gerçekleşen dural ponksiyon ile ilişkilidir. ${ }^{2}$ Pnömosefali semptomları intrakraniyal havanın dağılımı ve miktarına bağlıdır. Semptomlar baş ağrısı, yüksek kafa içi basıncı, kusma, kasılmalar ve dengesiz vital bulguları içerir. ${ }^{3}$ Kombine spinal epidural anestezi (KSEA) sonrasında nadir görülen bir komplikasyon olan pnömosefali olgusunu sunmayı amaçladık.

\section{OLGU SUNUMU}

71 yaşında bayan hastaya total diz replasmanı hem cerrahi anestezi için hem de etkin bir postoperatif analjezi sağlaması düşünülerek KSEA planlandı. Hastanın daha önce geçirilmiş omurga cerrahisi öyküsü mevcuttu. Lomber 3-4-5 vertebralarında bilateral vida enstrümantasyonu vardı. KSEA hava ile direnç kaybı yöntemi kullanılarak uygulandı. Lomber 3-4 intervertebral aralıktan 18G epidural iğne ile girilerek 6 cm'de epidural alana ulaşıldı. Epidural iğne içerisinden geçirilen $29 \mathrm{G}$ spinal iğne ile dura delinerek subaraknoid aralığa ulaşıldı. 12,5 mg bupivakain heavy (Buvasin heavy \%5, Turkey) uygulandı. Spinal iğnenin çıkarılması sonrasında epidural alanda $4 \mathrm{~cm}$ kalacak şekilde epidural kateter yerleştirildi. Kateter negatif aspirasyon ile kontrol edildi ve beyin omurilik sıvısı gelişi gözlenmemesi ve kateterin epidural alanda olduğu doğrulandıktan sonra kateter cilde sabitlenerek işlem sonlandırıldı. Hastanın postoperatif analjezi tedavisi epidural kateterden hasta kontrollü analjezi cihazı ile (bupivakain \%0,1 + fentanyl $2 \mu \mathrm{g} / \mathrm{ml}$ 'lik solusyondan $10 \mathrm{ml} /$ saat infüzyon) sağlandi. Postoperatif 20. saatte bilinç bulanıklığı, uykuya meyil ve konuşma güçlüğü başladı. Herhangi bir baş ağrısı şikayeti olmayan hastanın takiplerinde ilerleyen saatlerde bu şikayetleri arttı ve hastanın glaskow koma skalası (GKS)
10 (G3,V:3, M:4) olarak hesaplandı. Vital fonksiyonları ve biyokimyasal tetkikleri normaldi. Nöroloji konsültasyonu sonrasında tanısal beyin BT çekildi. Beyin BT görüntülemesinde interventriküler ve frontal alanda hava görünümü izlendi (Resim 1, 2). Pnömosefali tanısı ile takip edilmeye başlanan hasta monitörize bir şekilde hafif baş aşağ yatar pozisyonda ve maske ile oksijen tedavisi altında takip edildi. Postoperatif 48. saatte semptomları azalan hastada 4. günün sonunda GKS 15 idi ve nörolojik muayenesinde herhangi bir patoloji gözlenmedi. 7. gün yapılan beyin BT kontrolünde interventriküler ve frontal bölgedeki hava görüntülerinin tamamen yok olduğu görüldü. Hastanın nörolojik muayenesi tamamen normaldi ve mobilizasyonda da herhangi bir problem yoktu. 6 ay boyunca aralıklı olarak kontrol edilen hastada herhangi bir patolojiye rastlanmadi.

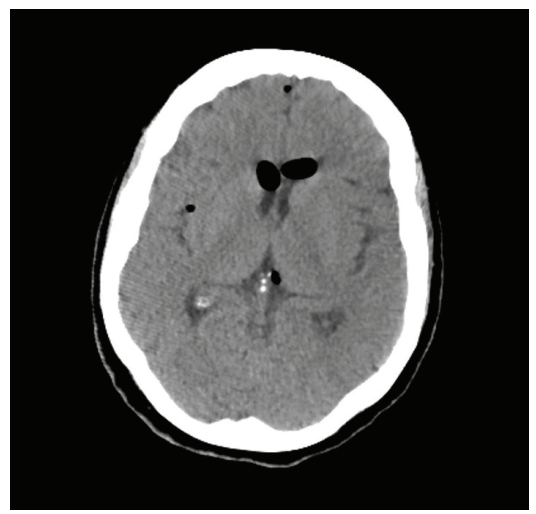

Şekil 1. Interventriküler alanda hava görünümü

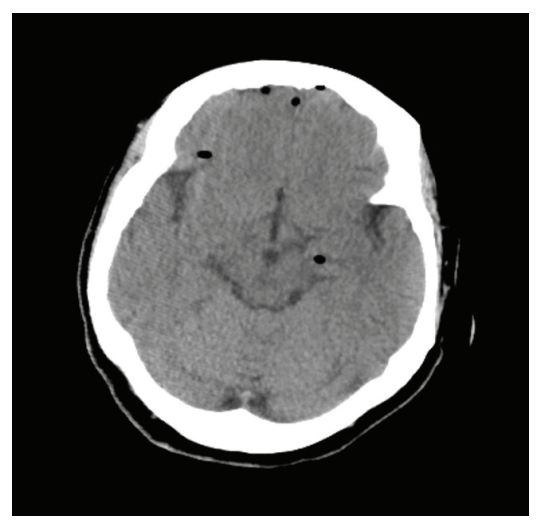

Şekil 2. Frontal alanda hava görünümü 


\section{TARTIŞMA}

Pnömosefali, istemsiz dural ponksiyon sırasında havanın subaraknoid veya subdural boşluktan kraniyuma geçişinden kaynaklanan nadir görülen bir komplikasyondur. ${ }^{4}$ Gómez-Ríos ve arkadaşları hava ile direnç kaybı yöntemi kullanılarak gelişen istemsiz dural ponksiyon sonrasında pnömosefali geliştiğini bildirmişlerdir. ${ }^{5}$ Benzer şekilde Wang ve arkadaşları ise lomber laminektomi geçirmiş hastada hava ile direnç kaybı yöntemi kullanarak epidural anestezi uygulaması sırasında istemsiz dural ponksiyon geliştiğini ve bunun sonucunda pnömosefali geliştiğini göstermişlerdir. ${ }^{6}$ Chew ve arkadaşları total diz replasman cerrahisi için hava ile direnç kaybı yöntemi uygulanan hastada dural ponksiyon olmamasına rağmen pnömosefali geliştiğini göstermişlerdir. ${ }^{7}$ Jones ve arkadaşları sıvı ile direnç kaybı yöntemiyle başarılı bir şekilde uyguladıkları epidural anestezi sonrasında ani gelişen başağrısı, takip eden günde ise tonik-klonik kasılmalar izlemişler ve non-operatif şekilde takip ederek hastanın iyileştiğini bildirmişlerdir. ${ }^{8}$ Lomber epidural steroid enjeksiyonu uygulanırken gelişen dural ponksiyon sonrasında hastada ani başağrısı gelişmesi üzerine BT görüntülenmesi yapılmış ve pnömosefali tanısı konulmuştur. Hastanın genel durumu değerlendirilerek konservatif tedavi (ağrı kesici, oksijen, $10^{\circ}$ baş aşağ 1 pozisyon) ile hasta takip edilmiş ve 2 . hafta alınan kontrol BT'de pnömosefalinin tamamen iyileștiği görülmüştür. ${ }^{9}$ Bizim hastamızda da epidural analjezi başarılı bir şekilde uygulanmasına rağmen hastada pnömosefali görülmüştür. Takipleri boyunca baş ağrısı ve konvülsiyon gelişmemesine rağmen gelişen bilinç bulanıklı̆̆ı bize pnömosefali tanısı açısından uyarıcı olmuştur. Cerrahi dışı tedavi; yüksek oksijen tedavisi (hızlı bir denitrojenasyon ve sıkışmış havanın yeniden emilmesi için), hastanın sırtüstü ya da trendelenburg pozisyonunda tutulması, profilaktik antibiyotik uygulaması, sık nörolojik muayeneler ve klinik bozulma meydana gelirse BT taramalarının tekrarlanmasını içerir. ${ }^{1}$

Bizim hipotezimiz, daha önce geçirilmiş omurga cerrahisine bağlı olarak epidural alanda yapışıklıklar gelişen hasta- da kesin bir dural ponksiyon olmasa bile epidural iğnenin duraya zarar verebileceğidir. Özellikle daha önce omurga cerrahisi geçiren hastalarda epidural anestezide sıvı ile direnç kaybı yönteminin kullanılmasının fark edilemeyen dura yaralanmasını ve pnömosefali gibi komplikasyonları azaltacağını düşünmekteyiz. Bu hasta gruplarında epidural anestezi sonrasında görülen baş ağrısı, bilinç bulanıklığı bulgularında nadir görülen pnömosefali komplikasyonunun akılda tutulmasını ve erken bir şekilde tedavi başlanmasının çok önemli olduğunu hatırlatmak istedik. 
Sakarya Tip Dergisi 2021;11(4):949-950

ȘAHIN ve Ark., Kombine Spinal Epidural Anestezi ile Pnömosefali

\section{Kaynaklar}

1. Schirmer CM, Heilman CB, Bhardwaj A. Pneumocephalus: Case illustrations and review. Neurocrit Care. 2010;13:152-8.

2. Aubrey V. Pneumocephalus after lumbar epidural steroid injection: a case report and review of the literature. A\& A Case Rep. 2014;3:9-13.

3. Civelek E, Ozcan AR, Aydin A, Erol G, Ebru EE. Complicated pneumocephalus after epidural anesthesia: a case report. Gulhane Med J. 2013;55:132e4.

4. Nafiu OO, Urquhart JC. Pneumocephalus with headache complicating labour epidural analgesia. Should we still be using air? Int J Obstet Anesth. 2006; 15:237-9.

5. Gómez-Ríos MÁ, Fernández-Goti MC. Pneumocephalus after inadvertent dural puncture during epidural anesthesia. Anesthesiology. 2013;118:444.
6. Wang JC, Tsai SH, Liao WI. Pneumocephalus after epidural anesthesia in an adult who has undergone lumbar laminectomy. J Neurosurg Anesthesiol. 2014;26:261-263.

7. Chew YW, Suppan VK, Ashutosh SR, Tew MM, Jimmy-Tan JH. Pneumocephalus Following Combined Spinal Epidural Anaesthesia for Total Knee Arthroplasty: A Case Report. Malaysian orthopaedic journal. 2017;11:42-44.

8. Jones JM, Gouveia JP, Rodrigues NM. Pneumocephalus and seizures following combined spinal-epidural for labor. J Clin Anesth. 2018;44:123-4.

9. Verdun AV, Cohen SP, Williams BS, Hurley RW. Pneumocephalus after lumbar epidural steroid injection: a case report and review of the literature. A A Case Rep. 2014;3:9-13. 